\title{
ESTIMASI PERHITUNGAN KALOR DAN LAJU ALIRAN KALOR PADA UNTAI FASSIP-02
}

\author{
Lutfi Fitria Ningsih ${ }^{1}$, Ahmad Rofiq Sofyan ${ }^{2}$, Giarno $^{3}$, \\ Dedy Haryanto ${ }^{3}$, Joko Prasetyo Witoko ${ }^{3}$, Mulya Juarsa ${ }^{3}$ \\ ${ }^{1}$ Mahasiswa Departemen Fisika, FMIPA Institut Teknologi Sepuluh Nopember Surabaya \\ ${ }^{2}$ Mahasiswa Departemen Fisika, FMIPA Universitas Padjajaran Bandung \\ ${ }^{3}$ Pusat Teknologi dan Keselamatan Reaktor Nuklir - BATAN
}

\begin{abstract}
ABSTRAK
ESTIMASI PERHITUNGAN KALOR DAN LAJU ALIRAN KALOR PADA UNTAI FASSIP02. Kecelakaan reaktor nuklir di Fukushima karena adanya gempa bumi yang menyebabkan tsunami sehingga mematikan sistem kelistrikan untuk pemompa air pendingin. Dari kejadian tersebut dibutuhkan suatu sistem pasif yang tidak membutuhkan energi dari luar untuk pendinginan darurat. Sistem pasif dibuat berdasarkan prinsip natural circulation (sirkulasi alami) dimana pergerakan molekul air karena adanya perubahan densitas ketika terjadi pemanasan. Untuk mengetahui bagaimana sistem Untai FASSIP-02 maka dilakukan pendekatan study literatur dan estimasi perhitungan kalor dan waktu penguapan air dalam tangki pendinginan air (water cooling tank / WCT). Selain itu juga dilakukanperhitungan laju aliran kalor dan waktu pemanasan air di kolam WCT hingga mencapai temperatur $100^{\circ}$ $\mathrm{C}$ berdasarkan ukuran geometri dan parameter yang telah ditentukan. Dari estimasi yang dilakukan diperoleh nilai kalor terbesar yaitu $18835340,38 \mathrm{~kJ}$ dan yang terkecil $3767068,07 \mathrm{~kJ}$. Waktu penguapan terbesar 10,9 hari dan terkecil 2,18 hari. Laju aliran kalor terbesar diperoleh 333,05 kW dan yang terkecil 4,16 kW dengan waktu pemanasan terbesar 151,86 jam dan terkecil 0,76 jam.
\end{abstract}

Kata kunci: estimasi, kalor, sirkulasi alami, sistem pasif, Untai FASSIP-02

\section{ABSTRACT}

ESTIMATION ON HEAT AND HEAT TRANSFER CALCULATION ON FASSIP-02 TEST LOOP. Nuclear reactor accident at Fukushima nuclear power plant is caused by earthquake and tsunami that shut the electricity down due to failure of primary cooling pumps. From this accident, a passive cooling system is required, that can work without external energy. Passive system is built on the principle of natural circulation, in which the movement of water is due to the changes in density as heating occurs. To understand the FASSIP-02, literature study has been done as well as the calculation estimation regarding the heat and time to evaporate the water inside the Water Cooling Tank (WCT). In addition, the heat transfer and time to increase the Emergency Cooling Tank's water temperature until $100{ }^{\circ} \mathrm{C}$ are also conducted based on dimensional geometric and parameters. From the estimation, the largest heating value is $18835340,38 \mathrm{~kJ}$ and the smallest is 3767068,07 $\mathrm{kJ}$. The largest evaporation time is 10.9 days and the smallest is 2.18 days. The largest heat flow rate is estimated to be $333.05 \mathrm{~kW}$ and the $4.16 \mathrm{~kW}$, with the largest heating time of 151.86 hours and the smallest of 0.76 hours.

Keywords: estimation, heat, natural circulation, passive system, FASSIP-02 Loop 


\section{PENDAHULUAN}

Kenaikan kebutuhan listrik tidak diikuti dengan kenaikan persediaan bahan bakar fosil atau batu bara sebagai sumber energi utama dalam pembangkit listrik. Ketua Umum Asosiasi Pertambangan Batu Bara Indonesia (APBI), Pandu Sjahrir mengungkapkan bahwa dengan persediaan batu bara yang ada saat ini, berpotensi terjadi krisis batu bara di Indonesia pada tahun $2035^{[1]}$. Oleh karena hal tersebut diperlukan sumber energi baru untuk memenuhi kebutuhan listrik, salah satunya yang saat ini sedang ramai dikembangkan yaitu listrik tenaga nuklir. Pembangkit Listrik Tenaga Nuklir (PLTN) ini merupakan suatu teknologi baru yang memanfaatkan energi dari reaksi fisi Uranium untuk menghasilkan uap sebagai penggerak turbin dan generator. Panas dari hasil reaksi fisi digunakan untuk menguapkan air pendingin, dan uap yang dihasilkan digunakan untuk memutar turbin dan generator. Energi panas yang dihasilkan oleh reaksi $1 \mathrm{~kg}$ uranium murni nilainya setara dengan 2.400 ton batu bara. Dengan demikian energi listrik yang dihasilkan oleh uranium ini jauh lebih besar dari energi listrik yang dihasilkan batu bara ${ }^{[2]}$.

Hingga tahun 2010 di seluruh dunia baik di negara maju maupun berkembang telah dioperasikan sebanyak 438 unit PLTN tersebar di 30 negara dengan kontribusi sekitar $18 \%$ dari pasokan tenaga listrik dunia dengan total pembangkitan dayanya mencapai $314 \mathrm{MWe}^{[2]}$. Seperti pembangkit listrik pada umumnya, keamanan dan keselamatan pembangkit listrik pun sangat diperlukan. Hal ini dikarenakan dalam Pembangkit Listrik Tenaga Nuklir pun juga rawan terjadi sebuah kecelakaan. Kecelakaankecelakaan yang pernah terjadi diantaranya yaitu Chernobyl, Three Mile Island, dan Fukhusima Daichi. Kecelakaan-kecelakaan tersebut sebagian besar terjadi karena tidak adanya pendingin untuk mendinginkan reaktor. Seperti yang terjadi di Fukushima Daichi Jepang, kecelakaan terjadi karena adanya tsunami dan luapan air melebihi batas ketinggian tembok penghalang sehingga air merendam generator cadangan. Kemudian generator rusak sehingga pendingin mati total. Energi thermal yang berlebih menyebabkan pelelehan logam Zirkonium dan bereaksi dengan air sehingga menghasilkan gas $\mathrm{H}_{2}$. Lalu $\mathrm{H}_{2}$ interaksi dengan $\mathrm{O}_{2}$ dan terjadi ledakan ${ }^{[3-4]}$.

Berdasarkan kecelakaan tersebut diperlukan suatu sistem keselamatan yang dapat menyelamatkan reaktor dari kecelakaan akibat gagal pendinginan. Sistem keselamatan yang saat ini ramai menjadi topik penelitian ilmuan nuklir yaitu mengenai sistem pendingin dengan sirkulasi tanpa bantuan dari energi luar. Saat ini PTKRN BATAN (Pusat Teknologi dan Keselamatan Reaktor Nuklir Badan Tenaga Nuklir Nasional) sedang mengembangkan penelitian mengenai sistem pendingin pasif tersebut. Sistem tersebut dinamai dengan Untai FASSIP-02 $2^{[5,6]}$ yang merupakan sistem keselamatan pasif generasi kedua yang dikembangkan oleh Tim Peneliti Termohidrolika Eksperimental PTKRN BATAN sebagai proyek Riset Program INSINAS Pratama Kemitraan antara PTKRN BATAN dan Fakultas Teknik Universitas Indonesia, dimulai dari tahun 2017 hingga $2019^{[7]}$. Sis- 
tem air pendingin ini dapat bersikulasi dengan tanpa menggunakan energi luar (natural circulation). Sistem ini memanfaatkan perbedaan densitas air karena adanya perbedaan temperatur antara tangki panas dan dingin. Pergerakan energi termal dari air terjadi akibat gaya apung dan gaya gravitasi yang terjadi pada air ${ }^{[8]}$. Sistem pendingin darurat dengan sirkulasi alami didesign dengan pendinginan yang bertahan hingga 72 jam. Oleh karena dilakukan estimasi perhitungan kalor, laju aliran kalor, dan waktu penguapan air pada tangki pendingin (water cooling tank / WCT).

\section{TEORI}

Natural circulation merupakan suatu proses pergerakan air tanpa adanya gaya pendorong dari luar. Pada natural circulation terdapat komponen penyusun berupa tangki pemanas dan kolam WCT dihubungkan dalam suatu loop tertutup dengan menggunakan pipa ${ }^{[4]}$. $\mathrm{Pa}-$ da sistem natural circulation ini tangki pemanas diletakkan pada tempat yang lebih rendah dari pada kolam WCT ${ }^{[9]}$. Pergerakan air ini terjadi karena adanya gaya gravitasi bumi dan gaya buoyancy (gaya apung). Proses natural circulation terjadi ketika air dalam tangki pemanas dipanaskan maka temperatur air naik sehingga densitasnya akan berkurang. Air yang mengalami penurunan densitas akan tergerak ke atas karena adanya gaya apung (buoyancy). Kemudian ketika sampai di kolam WCT maka akan terjadi pelepasan kalor yang dibawa air ke dalam air di kolam WCT. Air yang keluar dari pipa tembaga di kolam WCT akan turun temperaturnya. Densitas air akan menjadi lebih be- sar. Kemudian air tersebut akan turun dan masuk lagi ke dalam tangki pemanas ${ }^{[10]}$.Proses natural circulation dipengaruhi oleh panjang loop atau perbedaan ketinggian antara tangki pemanas dengan kolam WCT ${ }^{[11]}$.

Estimasi perhitungan kalor dan waktu yang dibutuhkan dilakukan dengan dua macam keadaan. Yang pertama yaitu ketika heater langsung ke dalam kolam WCT, dan yang kedua heater tidak kontak dengan kolam WCT. Pada estimasi dengan keadaan heater kontak langsung dengan WCT, kalor digunakan untuk menguapkan air dalam kolam WCT hingga habis. Berikut ini rumus yang digunakan untuk menghitung kalor dan waktu penguapan.

$$
\begin{aligned}
& Q_{\text {kenaikan suhu }}=m c_{P} \Delta T \\
& Q_{\text {penguapan }}=m h
\end{aligned}
$$

$Q_{\text {total }}=Q_{\text {kenaikan suhu air }}+Q_{\text {penguapan }}$

$$
\Delta t=\frac{Q_{\text {total }}}{\text { Pheater }}
$$

Dengan Q merupakan kalor (kJ), m adalah massa air kolam WCT $(\mathrm{kg}), \mathrm{c}_{\mathrm{p}}$ adalah kalor jenis air $\left(\mathrm{kJ} / \mathrm{kg}{ }^{\circ} \mathrm{C}\right), \Delta \mathrm{T}$ adalah perbedaan temperatur awal dan akhir air kolam WCT, dan h adalah entalpi penguapan $(\mathrm{kJ} / \mathrm{kg})$.

Keadaan kedua digunakan untuk estimasi perhitungan laju aliran kalor dan waktu untuk menaikkan air dalam kolam WCT hingga mencapai temperatur $100{ }^{\circ} \mathrm{C}$. Berikut ini rumus yang digunakan. 


$$
\begin{aligned}
& Q=m c_{P}\left(T_{a k h i r}-T_{a w a l}\right) \\
& q=\frac{m c_{P}\left(T_{a k h i r}-T_{a w a l}\right)}{\Delta t} \\
& \Delta t=\frac{Q}{q}
\end{aligned}
$$

Dengan Q adalah kalor (kJ), T adalah temperatur $\left({ }^{\circ} \mathrm{C}\right)$, dan adalah laju aliran massa $(\mathrm{kg} / \mathrm{s})$, dan q adalah laju aliran kalor $(\mathrm{kJ} / \mathrm{s})^{[12]}$.

Nilai massa jenis dan kalor jenis air berubah berdasarkan fungsi temperatur. Pada estimasi perhitungan ini dilakukan dengan menggunakan persamaan berikut.

$$
\begin{aligned}
\rho(T)= & 1000.07+0.02093 T \\
& -0.00602 T^{2}+0.0000162 T^{3} \\
C_{p}= & {\left[\frac{A+C T}{1+B T+D T^{2}}\right] \ldots \ldots \ldots \ldots }
\end{aligned}
$$

Dengan nilai $A=17,48908904, B=-1,67507 x$ $103, C=-0,03189591$, dan $D=-2,8748 \times 10^{-6}$ [13].

\section{METODE}

Alat yang digunakan sebagai objek estimasi yaitu untai FASSIP-02. Untai FASSIP-02 terdiri dari beberapa komponen utama Komponen tersebut antara lain tangki pemanas, tangko pendingin (kolam WCT), dan loop pipa tertutup. Pemanas terdiri dari tangki pemanas dan 4 buah heater dengan total daya $20 \mathrm{kWatt}$. Kolam WCT terbuat dari carbon steel dengan ukuran 3 x 1 x 2,75 meter. Untai pipa tertutup yang terdiri dari pipa SS 304, pipa pyrex, dan pipa tembaga sebagai heat exchanger. Serta terdapat alat pengukur tambahan yaitu thermo couple dan pressure transmitter. Berikut ini design untai FASSIP-02

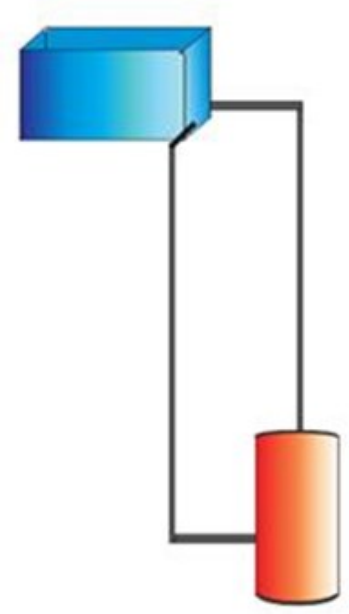

Gambar 1. Design Untai FASSIP-02

Penelitian dalam makalah ini dilakukan dengan pendekatan studi literatur dan estimasi perhitungan berdasarkan ukuran geometrik Untai FASSIP-02 dan parameter yang telah ditentukan. Parameter yang digunakan antara lain ketinggian air dalam kolam WCT, temperatur air saat masuk dan keluar dari pipa tembaga, laju aliran massa air. Pada kondisi pertama parameter ketinggian air yang digunakan yaitu 2,75 sampai 0,75 meter dengan beda setiap variasi 0,25 meter. Pada kondisi kedua parameter laju aliran massa yang digunakan sebesar $0,1,0,5$, dan 1 dalam satuan $\mathrm{kg} / \mathrm{s}$. Temperatur air masuk ke dalam pipa tembaga $90,80,70,60$, dan 50 dalam satuan $^{\circ} \mathrm{C}$. Temperatur air keluar dari pipa tembaga 40, 30, 20, dan 10 dalam satuan ${ }^{\circ} \mathrm{C}$. dan parameter ketinggian air dalam kolam 
WCT 2,5 m dan $1 \mathrm{~m}$. ini. Berikut ini alur yang dilakukan:

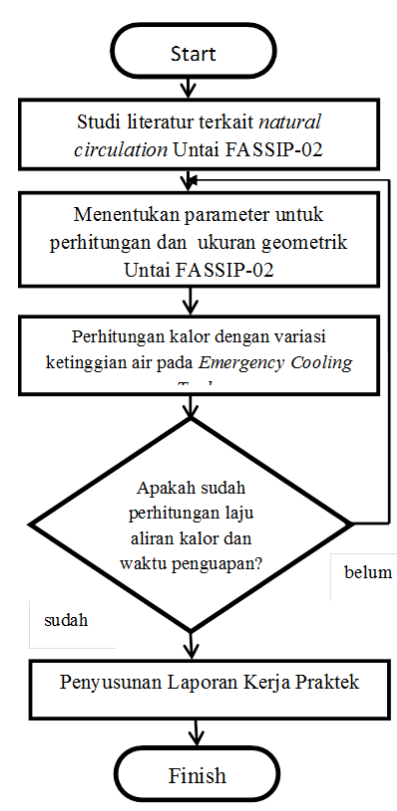

Gambar 2. Flowchart perhitungan

Untuk memperoleh estimasi perhitungan kalor dan waktu penguapan air kolam WCT serta laju aliran kalor dan waktu pemanasan digunakan persamaan 1 sampai 8 .

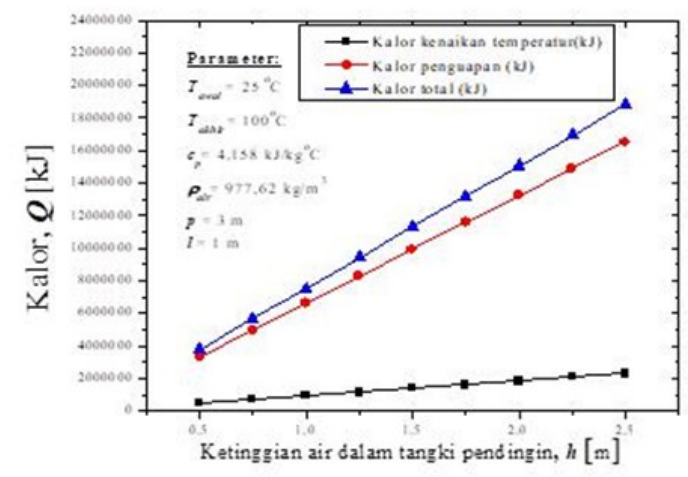

Gambar 3. Grafik hubungan antara kalor dengan ketinggian air dalam kolam WCT

\section{HASIL DAN PEMBAHASAN}

Berdasarkan perhitungan yang telah dilakukan diperoleh hasil perhitungan seperti berikut ini:

Tabel 1. Hasil perhitungan penguapan air

\begin{tabular}{|c|c|c|c|c|}
\hline $\begin{array}{c}H \\
(\mathrm{~m})\end{array}$ & $\begin{array}{c}Q_{\text {manemanana }} \\
\left(\mathrm{x} 10^{2} \mathrm{k} \mathrm{K}\right)\end{array}$ & $\begin{array}{l}Q_{\text {vaneasen }} \\
\left(\mathrm{xl} 0^{2} \mathrm{k} \mathrm{k}\right)\end{array}$ & $\underset{\left(\mathrm{x} 10^{2} \mathrm{k}\right)}{Q_{\text {nsed }}}$ & $\begin{array}{c}t \\
\text { (hari) }\end{array}$ \\
\hline 2,5 & 2286,62 & 16548,72 & 18835,34 & 10,9 \\
\hline 2.25 & 2057957,68 & 14893,84 & 16951.80 & 9,81 \\
\hline 2 & $1829,295,71$ & 13238,97 & 15068,27 & 8,72 \\
\hline 1,75 & $1600,633,75$ & 11584,10 & 13184,73 & 7,63 \\
\hline 1,5 & 137197 & 9929,23 & 11301,20 & 6,54 \\
\hline 1,25 & 1143,3 & 8274,36 & 9417,67 & 5,45 \\
\hline 1 & 914,64 & 6619,48 & 7534,13 & 4,36 \\
\hline 0,75 & 685,98 & 4964,61 & 5650,60 & 3,27 \\
\hline 0,5 & 457,32 & 3309,74 & 3767,06 & 2,18 \\
\hline
\end{tabular}

Hasil perhitungan yang diperoleh pada Tabel 1 dapat direpresentasikan ke dalam bentuk grafik pada Gambar 3 dan 4 berikut ini.

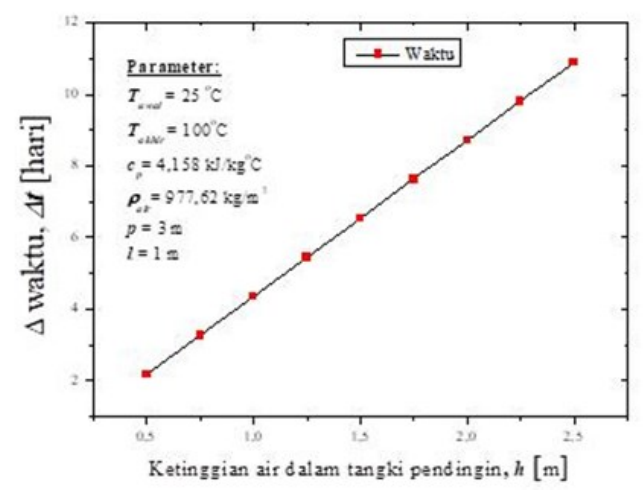

Gambar 4. Grafik hubungan antara waktu penguapan dengan ketinggian air dalam tangki pendingin 
Tabel 2. Hasil perhitungan pemanasan air WCT

\begin{tabular}{|c|c|c|c|c|}
\hline $\begin{array}{c}T_{\text {cin }} \\
\text { (C) }\end{array}$ & $\begin{array}{c}T_{\text {cos }} \\
(\mathrm{C})\end{array}$ & $\begin{array}{c}q \\
(\mathrm{kWatt})\end{array}$ & $Q$ (k) $)$ & $t(\mathrm{jam})$ \\
\hline 90 & 40 & 20,79 & 2277974 & 30,44 \\
\hline 90 & 30 & 24,96 & 2277974 & 25,35 \\
\hline 90 & 20 & 29,13 & 2277974 & 21,72 \\
\hline 90 & 10 & 33,31 & 2277974 & 19,00 \\
\hline 80 & 40 & 16,64 & 2277974 & 38,02 \\
\hline 80 & 30 & 20,81 & 2277974 & 30,41 \\
\hline 80 & 20 & 24,98 & 2277974 & 25,33 \\
\hline 80 & 10 & 29,16 & 2277974 & 21,70 \\
\hline 70 & 40 & 12,49 & 2277974 & 50,67 \\
\hline 70 & 30 & 16,66 & 2277974 & 37,99 \\
\hline 70 & 20 & 20,83 & 2277974 & 30,38 \\
\hline 70 & 10 & 25,01 & 2277974 & 25,30 \\
\hline 60 & 40 & 8,33 & 2277974 & 75,97 \\
\hline 60 & 30 & 12,50 & 2277974 & 50,62 \\
\hline 60 & 20 & 16,67 & 2277974 & 37,95 \\
\hline 60 & 10 & 20,85 & 2277974 & 30,35 \\
\hline 50 & 40 & 4,17 & 2277974 & 151,86 \\
\hline 50 & 30 & 8,34 & 2277974 & 75,90 \\
\hline 50 & 20 & 12,51 & 2277974 & 50,58 \\
\hline 50 & 10 & 16,69 & 2277974 & 37,92 \\
\hline
\end{tabular}

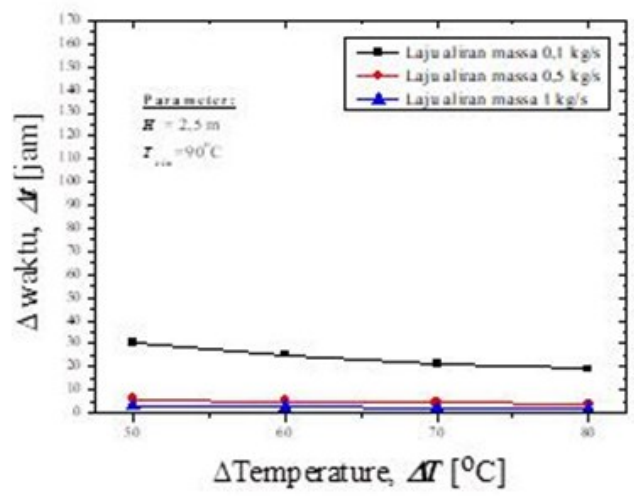

Gambar 6. Grafik hubungan antara waktu pemanasan dan beda temperatur saat ketinggian $2,5 \mathrm{~m}$ dan $\mathrm{T}_{\text {cin }} 90^{\circ} \mathrm{C}$

Berdasarkan grafik Gambar 3 diperoleh hasil bahwa kalor yang dibutuhkan untuk memanaskan dan menguapkan air di dalam kolam WCT akan semakin besar seiring dengan meningkatnya ketinggian air dalam kolam WCT. Hal ini karena semakin besar

Dari perhitungan di atas dapat direpresentasikan sebagai grafik dalam Gambar 5 dan 6 seperti berikut ini.

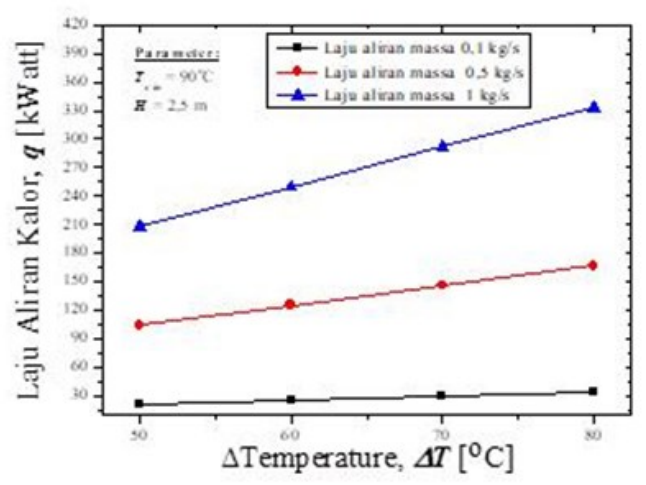

Gambar 5. Grafik hubungan antara laju aliran kalor dan beda temperatur saat ketinggian 2,5 m dan $\mathrm{T}_{\text {cin }} 90^{\circ} \mathrm{C}$ semakin besar pula volume di dalamnya. Sehingga semakin besar volume air maka juga akan semakin besar pula massa air di dalam tangki tersebut. Dan hal ini mengakibatkan kalor yang dibutuhkan untuk menguapkan air kolam WCT hingga habis juga akan semakin lebih besar. Jadi hubungan antara ketinggian air dalam kolam WCT dan kalor yang dibutuhkan untuk penguapan berbanding lurus. Begitu juga berdasarkan grafik pada Gambar 4 untuk waktu penguapan hingga air dalam tangki habis akan semakin lebih besar jika ketinggian air dalam kolam WCT semakin besar. Hal ini berkaitan dengan kalor yang dibutuhkan untuk penguapan. Semakin besar ketinggian maka akan semakin besar pula kalor yang dibutuhkan. Pada Untai FASSIP- 
02 ini digunakan heater dengan daya total 20 kWatt. Sehingga semakin besar kalor yang dibutuhkan sementara daya heater tetap maka akan semakin besar waktu yang dibutuhkan untuk penguapan. Sehingga waktu penguapan juga berbanding lurus dengan ketinggian air dalam kolam WCT.

Keadaan yang kedua dengan asumsi heater tidak langsung kontak dengan kolam WCT, dilakukan untuk estimasi perhitungan laju aliran kalor dan waktu yng dibutuhkan untuk menaikkan temperatur air di dalam kolam WCT dari $25{ }^{\circ} \mathrm{C}$ sampai $100{ }^{\circ} \mathrm{C}$. Berdasarkan hasil perhitungan dan grafik pada Gambar 5 dapat diperoleh bahwa nilai dari laju aliran kalor dipengaruhi oleh beberapa hal. Yang pertama yaitu laju aliran massa air, dan perbedaan temperatur air ketika memasuki pipa tembaga dan tempertur air ketika keluar dari pipa tembaga. Berdasarkan dari grafik, dengan laju aliran massa air yang sama nilai laju aliran kalor berbanding lurus dengan perbedaan temperatur $\mathrm{T}_{\text {cin }}$ dan $T_{\text {cout }}$ Semakin besar delta temperatur antara $T_{\text {cin }}$ dan $\mathrm{T}_{\text {cout }}$ maka akan semakin besar nilai laju aliran kalornya. Hal ini menunjukkan bahwa dengan perbedaan temperatur yang semakin besar maka perpindahan kalor dari dalam pipa tembaga menuju air di dalam kolam WCT akan semakin besar. Hal ini dikarenakan kalor dari temperatur yang lebih tinggi akan lebih mudah dipindahkan ke temperatur rendah. Mudahnya perpindahan kalor ini karena pada temperatur yang lebih tinggi densitas air akan semakin lebih kecil. Sehingga semakin kecil densitasnya maka air tersebut akan semakin mudah untuk dipindahkan sehingga laju aliran massa akan menjadi lebih besar. Selain delta temperatur antara $T_{\text {cin }}$ dan $T_{\text {cout }}$, laju aliran kalor juga dipengaruhi oleh laju aliran massa air. Berdasarkan grafik pada Gambar 5 semakin besar laju aliran massa maka laju aliran kalor akan semakin besar. Hal ini karena semakin besar nilai laju aliran massa air maka kalor yang dipindahkan bersama dengan air tersebut akan semakin besar pula.

Estimasi perhitungan waktu yang dibutuhkan untuk meningkatkan air dalam kolam WCT dipengaruhi oleh ketinggian air dalam kolam WCT dan laju aliran kalor yang terjadi pada pipa tembaga atau heat exchanger. Berdasarkan grafik yang terdapat pada Gambar 6 semakin besar beda temperatur maka akan semakin cepat waktu yang dibutuhkan untuk mencapai temperatur $100{ }^{\circ} \mathrm{C}$. Dengan ketinggian air dalam kolam WCT yang sama, maka kalor yang dibutuhkan untuk meningkatkan temperatur juga sama. Sehingga yang berpengaruh terhadap waktu pemanasan air dalam kolam WCT yaitu perbedaan suhu dan laju aliran massa. Waktu pemanasan berbanding terbalik dengan perbedaan suhu, laju aliran massa, dan laju aliran kalor. Semakin besar perbedaan temperatur $\mathrm{T}_{\text {cin }}$ dan $\mathrm{T}_{\text {cout }}$ dan laju aliran massa air maka akan semakin besar kalor yang dipindahkan. Sehingga waktu untuk pemanasan akan semakin kecil. 


\section{KESIMPULAN}

Kalor yang dibutuhkan untuk untuk menguapkan air dalam kolam WCT yang terbesar yaitu sebesar 18835340,38 kJ pada saat ketinggian air dalam kolam WCT 2,5 m, dan yang terkecil yaitu sebesar 3767068,07 kJ dengan ketinggian air dalam kolam WCT 0,5 m. Waktu yang dibutuhkan untuk untuk menguapkan air dalam kolam WCT yang terbesar yaitu sebesar 10,9 hari dicapai pada saat ketinggian air dalam kolam WCT 2,5 m, dan yang terkecil yaitu sebesar 2,18 hari dengan ketinggian air dalam kolam WCT 0,5 m. Laju aliran kalor yang digunakan untuk untuk memanaskan air dalam kolam WCT hingga mencapai temperatur $100^{\circ}$ C yang terbesar yaitu sebesar $333,05 \mathrm{~kW}$ pada saat aliran massa air sebesar dan delta temperatur antara air yang masuk dan keluar pada pipa tembaga sebesar, dan yang $1 \mathrm{~kg} / \mathrm{s}$ dan $80{ }^{\circ} \mathrm{C}$, laju aliran kalor terkecil yaitu sebesar 4,16 kWatt pada saat aliran massa air sebesar dan delta temperatur antara air yang masuk dan keluar pada pipa tembaga sebesar, dan yang $0,1 \mathrm{~kg} / \mathrm{s}$ dan $10{ }^{\circ} \mathrm{C}$. Waktu yang digunakan untuk untuk memanaskan air dalam kolam WCT hingga mencapai temperatur $100{ }^{\circ} \mathrm{C}$ yang terbesar yaitu sebesar 151,86 jam pada saat laju aliran massa air, ketinggian air kolam WCT dan delta temperatur antara air yang masuk dan keluar pada pipa tembaga sebesar $0,1 \mathrm{~kg} / \mathrm{s}, 2,5$ $\mathrm{m}$ dan $80{ }^{\circ} \mathrm{C}$, laju aliran kalor waktu terkecil yaitu sebesar 0,76 jam pada saat aliran massa air, ketinggian air kolam WCT dan delta temperatur antara air yang masuk dan keluar pada pipa tembaga sebesar $1 \mathrm{~kg} / \mathrm{s}, 1 \mathrm{~m}$ dan $10{ }^{\circ} \mathrm{C}$.

\section{UCAPAN TERIMA KASIH}

Penulis mengucapkan terima kasih kepada Kepala PTKRN-BATAN atas ijinnya untuk melakukan kerja praktek dan penggunaan fasilitas di laboratorium Termohidrolik Eksperimental. Ucapan terima kasih juga diberikan kepada Program INSINAS Pratama Kemitraan dari KEMENRISTEKDIKTI antara PTKRN-BATAN dan Fakultas Teknik Universitas Indonesia dengan nomor kontrak 02/INS-2/PPK/E/E4/2017

\section{DAFTAR PUSTAKA}

1. Ariyanti, diambil dari http:// bisnis.liputan6.com/read/2595197/ indonesia-terancam-krisis-batu-bara-di2035 diakses pada 15 Juli 2017 pukul 16.55

2. Media Infomasi Ilmu Pengetahuan dan Teknologi Nuklir, "Pengenalan Pembangkit Listrik Tenaga Nuklir", Jakarta, BATAN

3. M. Juarsa, J.H. Purba, H.M. Kusuma, T. Setiadipura, S. Widodo, Atom, 40 (3), 141 - 147 (2014)

4. M. Holt, R. J. Campbell, M. B. Nikitin, "Fukushima Nuclear Disaster". Congressional Research Service 7-5700, 2012

5. M. Juarsa, A. R. Antariksawan, M. H. Kusuma, D. Haryanto, Nandy Putra, Estimation of Natural Circulation Flow Based on Temperature in the FASSIP02 Large-Scale Test Loop Facility, The 2nd International Tropical Renewable 
Energy Conference (i-TREC) 2017, BaliIndonesia 3-4 October 2017 (published in IOP Conf. Series: Earth and Environmental Science 105 (2017)).

6. A. R. Antariksawan, S. Widodo, M. Juarsa, Dedy Haryanto, M. H. Kusuma, Nandy Putra, Numerical study on natural circulation characteristics in FASSIP-02 experimental facility using RELAP5 code, The 2nd International Tropical Renewable Energy, Bali-Indonesia 3-4 October 2017 (published in IOP Conf. Series: Earth and Environmental Science 105 (2017)).

7. Ditjen Penguatan Riset dan Pengembangan Kementrian Riset, Teknologi, dan Pendidikan Tinggi, diambil dari simlitabmas.ristekdikti.go.id, diakses pada tanggal 25 Juli 2017 Pukul 7.50 WIB

8. Y. Zvirin, A Review Of Natural circulation Loop In Pressurized Water Reactors and Other System, USA, Palo Alto, 1981.

9. International Atomic Energy Agency, Natural circulation Phenomena and Modelling for Advanced Water Cooled Reactors, IAEA-TECDOC-1677, Vienna, 2012.

10. International Atomic Energy Agency, Passive Safety Systems and Natural circulation in Water Cooled Nuclear Power Plants, IAEA-TECDOC-1677, Vienna, 2009.

11. A. G. Abdullah, N.P. Ardiansyah, W.Purnama, Jurnal Pendidikan Fisika Indonesia 10 (2), 168 - 177 (2014).
12. J. P. Holman, Thermodynamics 4th Edition". Singapore: McGraw Hill International Edition, 1998.

13. A. Crabtree and M. Siman-Tov, Thermophysical Properties of Saturated Light and Heavy Water for Advanced Neutron Source Applications. Oak Ridge National Lab., Tn (United States), 1993. 